\title{
The clinical activity of arsenic trioxide, ascorbic acid, ifosfamide and prednisone combination therapy in patients with relapsed and refractory multiple myeloma
}

This article was published in the following Dove Press journal:

OncoTargets and Therapy

9 April 2015

Number of times this article has been viewed

Xin $\mathrm{Li}^{1, *}$

Wan-Jun Sun ${ }^{2, *}$

'Department of Hematology and Oncology, Beijing Chaoyang Hospital, Capital Medical University, ${ }^{2}$ Department of Hematology, Second Artillery General Hospital, Beijing, People's Republic of China

*These authors contributed equally to this work
Correspondence: Xin Li Department of Hematology and Oncology, Beijing Chaoyang Hospital, Capital Medical University, Jingyuan Road, Beijing, I00043, People's Republic of China

Tel +86 I0 517। 8442

Fax +86 I0 6634335 ।

Email lixin0628@sohu.com
Abstract: This study aimed to investigate the activity of arsenic trioxide $\left(\mathrm{As}_{2} \mathrm{O}_{3}\right)$ combined with ascorbic acid, ifosfamide, and prednisone chemotherapy in patients with repeatedly relapsed and refractory multiple myeloma (MM). Here, we retrospectively analyzed medical data of $30 \mathrm{MM}$ patients showing progressive disease after receiving at least two previous lines of treatment including an immunomodulatory agent (thalidomide or lenalidomide) and a proteasome inhibitor. There were 19 men and eleven women, aged 54-73 (median 65) years, in this study. The distribution of different isotypes included immunoglobulin $\mathrm{G}(\mathrm{IgG})$ (12 patients), $\operatorname{IgA}$ (six patients), IgD (three), and light chain (nine patients). All the patients were DurieSalmon stage III and had relapsed at least three times; the median cycles of prior therapies was 15 (range 10-18). The patients were treated with $\mathrm{As}_{2} \mathrm{O}_{3}$, ascorbic acid, and $\mathrm{CP}$ (ifosfamide $1 \mathrm{~g}$ on day 1 , day 3 , day 5, and day 7; prednisone $30 \mathrm{mg}$ taken orally for 2 weeks). $\mathrm{As}_{2} \mathrm{O}_{3}$ was administered as an intravenous infusion at a dose of $10 \mathrm{mg} / \mathrm{d}$ and ascorbic acid at a dose of $2 \mathrm{~g} / \mathrm{d}$ for 14 days of each 4-week cycle. The results showed that after 2 cycles of therapy, there were five patients that attained partial response, 15 had minimal response, five had no change, and five had progressive disease. The overall response rate was $66.7 \%$ (20/30 cases), 50\% (10/20 cases), and 40\% (2/5 cases), respectively, after 2,4 , and 6 cycles of the therapy. But there were no patients that attained complete remission. The median time of overall survival and progression-free survival were 48 (29-120) and 6 (2-8) months, respectively. The most common treatment-related adverse events included neutropenia, fatigue, anemia, thrombocytopenia, and infection that could be tolerated. The results showed that $\mathrm{As}_{2} \mathrm{O}_{3}$ combined with ascorbic acid, ifosfamide, and prednisone chemotherapy may be a choice treatment for repeatedly relapsed and refractory MM patients.

Keywords: chemotherapy, response

\section{Introduction}

Over the past decade, increasing knowledge of multiple myeloma (MM) biology has already been contributing to a more specific drug design, and we have recently learned that in the pathogenesis of MM, as important as the malignant cells themselves is their interaction with the microenvironment. Bortezomib and lenalidomide have returned a remarkable treatment response in recent years, but MM patients have still inevitably relapsed. ${ }^{1} \mathrm{MM}$ remains an incurable disease for now, with median survival rates of 4-6 years. Thus, newer treatments with good safety profiles are needed to improve the quality of responses, prolong progression, and increase overall survival (OS). 
Arsenic trioxide $\left(\mathrm{As}_{2} \mathrm{O}_{3}\right)$ is a promising compound to explore in MM because of its multifaceted antitumor activity. ${ }^{2,3}$ In this study, we explored the clinical activity of $\mathrm{As}_{2} \mathrm{O}_{3}$ combined with chemotherapy for relapsed and refractory $\mathrm{MM}$ after bortezomib and lenalidomide treatment. In the modern era, interest in arsenic as a chemotherapy was rekindled after it was identified as an active ingredient in traditional medicines in the People's Republic of China. ${ }^{4} \mathrm{As}_{2} \mathrm{O}_{3}$ affects multiple cellular functions via different molecular targets. $\mathrm{As}_{2} \mathrm{O}_{3}$ targets the mitochondria, decreasing the mitochondrial membrane potential $(\Delta \Psi \mathrm{m})$ via multiple specific targets, including Bcl-2 and the permeability transition pore complex. ${ }^{5}$ This change in potential results in the release of cytochrome $\mathrm{C}$, which activates the caspase cascade. It also results in increased release of reactive oxygen species (ROS) from the mitochondria. ROS levels are increased further by $\mathrm{As}_{2} \mathrm{O}_{3}$ inhibition of the antioxidant enzyme GPx. ${ }^{6} \mathrm{As}_{2} \mathrm{O}_{3}$ also inhibits activation of the cell-survival factor NF- $\kappa B$ via inhibition of IKK, the kinase responsible for releasing NF- $\mathrm{KB}$ that is sequestered in the cytoplasm. ${ }^{7}$

A multicenter trial confirmed the role of $\mathrm{As}_{2} \mathrm{O}_{3}$ in the management of relapsed or refractory MM using a higher dose and shorter schedule. Nine (43\%) of 21 evaluated patients had an objective response. One patient with refractory disease had a 50\% decrease in plasmacytoma size, eight patients had stable disease, and four had progressive disease (PD) at the first evaluation visit. ${ }^{8}$ So single-agent $\mathrm{As}_{2} \mathrm{O}_{3}$ for MM was not satisfactory. Wang and Fang ${ }^{9}$ reported that $\mathrm{As}_{2} \mathrm{O}_{3}$, ginseng saponin, and beta-elemene can inhibit the growth and telomerase activity of K562 cells. The inhibiting effects were enhanced when they were used in combination with cyclophosphamide. Ifosfamide is a common drug to treat $\mathrm{MM}$, and arsenic is a routine drug for treating hematology diseases, especially for acute promyelocytic leukemia (APL), in the People's Republic of China, so we attempted to treat MM with the combination of arsenic, ifosfamide, ascorbic acid, and prednisone.

\section{Materials and methods \\ Patients}

We retrospective analyzed 30 cases of patients with relapsed and refractory MM from Beijing Chao-yang Hospital of Capital Medical University and the Second Artillery General Hospital from September 2007 to March 2014. All the patients were Durie-Salmon stage III and had relapsed at least three times; the median number of prior chemotherapy cycles was 15 (range, 10-18) before using
$\mathrm{As}_{2} \mathrm{O}_{3}$. Five patients had received autologous stem cell transplantation. There were five patients at stage II and 25 patients at stage III, according to the International Staging System. ${ }^{10}$ The median time from diagnosis to receive the $\mathrm{As}_{2} \mathrm{O}_{3}$ with ascorbic acid, ifosfamide, and prednisone was 40 (35-69) months for the patients in this study. This study was approved by the Chinese Medical Ethics Committee, and work was undertaken in conformity with the provisions of the Declaration of Helsinki. Consents were obtained from the patients.

\section{Combination therapy with $\mathrm{As}_{2} \mathrm{O}_{3}$, ascorbic acid, ifosfamide, and prednisone}

All the patients treated with $\mathrm{As}_{2} \mathrm{O}_{3}$, ascorbic acid, and CP (ifosfamide $1 \mathrm{~g}$ intravenous [IV] drip on day 1 , day 3 , day 5 , and day 7; prednisone $30 \mathrm{mg}$ taken orally [PO] for 2 weeks). $\mathrm{As}_{2} \mathrm{O}_{3}$, was administered as an IV infusion at a dose of $10 \mathrm{mg} / \mathrm{d}$ and ascorbic acid at a dose of $2 \mathrm{~g} / \mathrm{d}$ for 14 days of each 4-week cycle. The infusion was administered over 2 hours unless adverse effects occurred, in which case the infusion was given over 4 hours.

\section{Assessment of efficacy and safety}

The cutoff date for response and survival data was October 3 , 2014. Patients who received at least 2 full cycles were evaluable for efficacy. Response to treatment was assessed by quantification of MM parameters (serum and urine protein electrophoresis and immunofixation, with quantification of the M-protein, Bence-Jones proteins in urine, b2-microglobulin, and C-reactive protein) at screening and at every 2 cycles during the treatment period. We used the criteria of European Group for Blood and Marrow Transplantation (EBMT) for evaluating disease response and progression in patients with MM treated by highdose therapy and hemopoietic stem cell transplantation. ${ }^{11}$ The criteria of response include complete remission (CR), partial response (PR), minimal response (MR), no change (NC), and $\mathrm{PD}$. We observed the overall response rate $(\mathrm{ORR})(\mathrm{ORR}=\mathrm{CR}+$ $\mathrm{PR}+\mathrm{MR})$. The criteria for relapse were any one or more of the following: reappearance of serum or urine M-protein by immunofixation or electrophoresis, development of 5\% plasma cells in the bone marrow, or appearance of any other sign of progression (ie, new plasmacytoma, lytic bone lesion, or hypercalcemia). Patients with relapsed and refractory MM that had at least two previous lines of treatment including an immunomodulatory agent (thalidomide or lenalidomide) and proteasome inhibitors showing PD, as defined by the International Myeloma Working Group (IMWG) criteria, were included. ${ }^{12}$ 
Safety was assessed during the therapy of $\mathrm{As}_{2} \mathrm{O}_{3}$, administration. Laboratory studies (blood counts, electrolyte panels, urinalysis, liver function tests, and serum tumor marker analysis) and physical examinations (ECGs, echocardiograms, chest X-rays, dermatologic and neurologic consults, and nerve conduction velocity tests) were performed during therapy.

Safety was assessed by a numerical tabulation of adverse events, assessed in accordance with the National Cancer Institute (NCI) Common Toxicity Criteria, version 2, eg, grade 1 neutropenia was defined as an absolute neutrophil count (ANC) of 1,500-1,900 for grade 1; 1,000-14,000 for grade $2 ; 500-900$ for grade 3 .

\section{Statistical analysis}

The Kaplan-Meier method was used to estimate the probability of progression-free survival (PFS) and OS. OS was defined as the time from registration to death or censoring of the patient data. PFS was defined as the time relapsed between the beginning of treatment with $\mathrm{As}_{2} \mathrm{O}_{3}$ and tumor progression or death from any cause.

\section{Results}

\section{Basic clinical characteristics of patients}

From September 2007 to March 2014, 30 cases of relapsed and refractory MM patients were involved in this study. Patient charts were retrospectively reviewed to collect the follow-up data. There were 19 men and eleven women aged 54-73 (median 65) years in this study (Table 1). The distribution of different isotypes included immunoglobulin (Ig)G (12 patients), IgA (six patients), IgD (three patients), and light chain (nine patients). The median number of cycles of prior chemotherapy was $15(10-18)$. All the patients had relapsed at least three times and then received more than two lines of chemotherapy after relapse, so all the patients were refractory. The most common prior therapies (first-line chemotherapy) were VAD (vincristine, doxorubicin, and dexamethasone), TD (thalidomide and dexamethasone), M2 (melphalan, carmustine, cyclophosphamide, vincristine, and prednisone), and bortezomib and LD (lenalidomide and dexamethasone). Five patients relapsed after receiving autologous stem cell transplant, and five patients had extramedullary plasmacytomas, in this study. There were 28 patients who received therapy with bortezomib and there were 15 patients had received lenalidomide after relapse. The second-line chemotherapies were DECP (cisplatin, etoposide, cyclophosphamide, and prednisone), VAMP (vincristine, doxorubicin, and methylprednisolone),
Table I Patient characteristics $(n=30)$

\begin{tabular}{|c|c|}
\hline Characteristic & $\begin{array}{l}\text { Number of } \\
\text { patients, } n=30\end{array}$ \\
\hline Age, yrs & $65(54-73)$ \\
\hline Male/female & $19 / 11$ \\
\hline WBC count $\left(\times 10^{9} / L\right)$ & $4.7(1.0-11.6)$ \\
\hline Platelets $\left(\times 10^{9} / \mathrm{L}\right)$ & $159(47-362)$ \\
\hline Hemoglobin (g/dL) & $98(62-125)$ \\
\hline B2-MG (mg/L) & $7.25(1.75-38.15)$ \\
\hline $\operatorname{ESR}(\mathrm{mm} / \mathrm{h})$ & $70(30-135)$ \\
\hline Plasma cell aspirate (\%) of bone marrow & $49(32-85)$ \\
\hline Number of previous therapies & $15(10-18)$ \\
\hline \multicolumn{2}{|l|}{ Type of diseases } \\
\hline $\lg G / \kappa$ & 8 \\
\hline $\lg G / \lambda$ & 4 \\
\hline $\lg A / \kappa$ & 6 \\
\hline $\lg \mathrm{D} / \lambda$ & 3 \\
\hline$\lambda$ light chain & 6 \\
\hline$\kappa$ light chain & 3 \\
\hline \multicolumn{2}{|l|}{ Durie-Salmon stage } \\
\hline III A & 28 \\
\hline II B & 2 \\
\hline \multicolumn{2}{|l|}{ ISS stage } \\
\hline II & 5 \\
\hline III & 25 \\
\hline \multicolumn{2}{|c|}{$\begin{array}{l}\text { Number of previous therapies before arsenic } \\
\text { trioxide treatment, as first-line therapy }\end{array}$} \\
\hline VAD & $26(86.7)$ \\
\hline M2 & $19(63.3)$ \\
\hline TD & $30(100)$ \\
\hline Bortezomib & $28(96.7)$ \\
\hline LD & $15(50)$ \\
\hline Autologous stem cell transplantation & $5(16.7)$ \\
\hline \multirow{2}{*}{\multicolumn{2}{|c|}{$\begin{array}{l}\text { Number of previous therapies before arsenic } \\
\text { trioxide treatment as second-line therapy }\end{array}$}} \\
\hline & \\
\hline DECP & $25(83.3)$ \\
\hline VAMP & $15(50)$ \\
\hline$A B V D$ & $6(20)$ \\
\hline
\end{tabular}

Notes: Values are expressed as median (range or percent). VAD, vincristine, doxorubicin, and dexamethasone; M2, melphalan, carmustine, cyclophosphamide, vincristine, and prednisone; TD, thalidomide and dexamethasone; $L D$, lenalidomide and dexamethasone; DECP, cisplatin, etoposide, cyclophosphamide, and prednisone; VAMP, vincristine, doxorubicin, and methylprednisolone; and ABVD, vincristine, doxorubicin, carmustine, and dexamethasone.

Abbreviations: B2-MG, b2-microglobulin; ESR, estimated sedimentation rate; Ig, immunoglobulin; ISS, International Staging System; WBC, white blood cells; yrs, years.

and ABVD (vincristine, doxorubicin, carmustine, and dexamethasone).

\section{Patient disposition and efficacy}

A total of 30 patients completed at least 2 cycles of $\mathrm{As}_{2} \mathrm{O}_{3}$ combined with ascorbic acid, ifosfamide, and prednisone chemotherapy. After 2 cycles of therapy, there were five patients who attained PR, 15 that had MR, five that had $\mathrm{NC}$, and five that had PD. The ten patients with $\mathrm{NC}$ and PD changed to another treatment scheme. Thus, 20 patients 


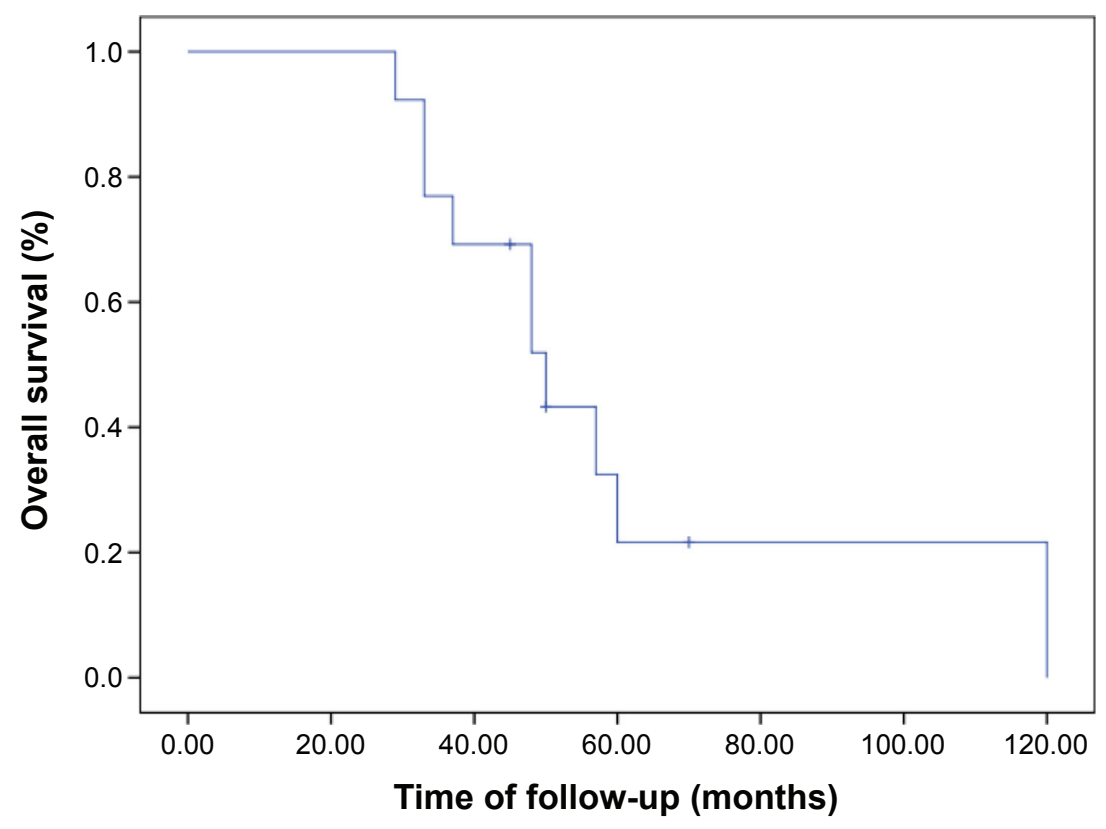

Figure I The time of OS for the relapse and refractory MM patients treated with arsenic trioxide, ascorbic acid, ifosfamide, and prednisone. Abbreviations: MM, multiple myeloma; OS, overall survival.

completed 4 cycles of $\mathrm{As}_{2} \mathrm{O}_{3}$ combined with ascorbic acid, ifosfamide, and prednisone chemotherapy. Of these, five patients achieved PR, five had MR, seven had NC, and three had PD. Only five PR patients completed 6 cycles of therapy, while the seven NC, three PD, and five MR patients changed to another scheme, with one patient attaining PR, one having $\mathrm{MR}$, one having $\mathrm{NC}$, and two having PD (Table 2). The ORR was $66.7 \%$ (20/30 cases), 50\% (10/20 cases), and 40\% (2/5 cases), respectively, after 2,4 , and 6 cycles of the therapy. But there were no patients who attained CR. The ten patients with PD died, all from PD.

There were 12 IgG-subtype MM patients who finished 2 cycles of chemotherapy, and three patients attained PR, five had MR, two had NC, and two had PD. Ten IgG-subtype MM patients finished 4 cycles of chemotherapy: two attained PR, two had MR, four had NC, and two had PD. There were two IgG-subtype patients that finished 6 cycles of chemotherapy: one attained PR and one had NC. There were six IgA-subtype MM patients that finished 2 cycles of chemotherapy: one attained PR, two had MR, two had NC, and one had PD. There were six IgA-subtype patients that finished 4 cycles of chemotherapy: two attained PR, two had MR, one had $\mathrm{NC}$, and one had PD. Only one IgA-subtype patient finished 6 cycles of chemotherapy and attained MR. Three IgDsubtype MM patients finished 2 cycles of chemotherapy: two patients attained MR and one had PD. Only one IgD-subtype patient finished 4 cycles of chemotherapy and attained NC. Nine light chain MM patients finished 2 cycles of chemotherapy: one patient attained PR, six had MR, one had $\mathrm{NC}$, and one had PD. Three light chain MM patients finished 4 cycles of chemotherapy: one attained PR, one had MR, and one had NC. Two light chain patients finished 6 cycles of chemotherapy and attained PD. The median time of OS and PFS were 48 (29-120) and 6 (2-8) months, respectively (Figures 1 and 2).

\section{Adverse events}

In all, 25 patients developed neutropenia (1-2 grade), with 16 of these patients experiencing thrombocytopenia and 21 patients developing anemia. Only five patients felt nausea, but 22 patients reported fatigue. Eight patients developed infections (three had pneumonia, four had acute upper

Table 2 Response of MM patients of relapsed and refractory to $\mathrm{As}_{2} \mathrm{O}_{3}$ combined with ascorbic acid, ifosfamide, and prednisone (\%)

\begin{tabular}{llllllll}
\hline & $\mathbf{N}$ & ORR (\%) & CR (\%) & PR (\%) & MR (\%) & NC (\%) & PD (\%) \\
\hline 2 cycles & 30 & $20(66.7 \%)$ & 0 & $5(16.7)$ & $15(50)$ & $5(16.7)$ & $5(16.7)$ \\
4 cycles & 20 & $10(50 \%)$ & 0 & $5(25)$ & $5(25)$ & $7(35)$ & $3(15)$ \\
6 cycles & 5 & $2(40 \%)$ & 0 & $1(20)$ & I (20) & I (20) & $2(40)$ \\
\hline
\end{tabular}

Abbreviations: $\mathrm{As}_{2} \mathrm{O}_{3}$, arsenic trioxide; $\mathrm{CR}$, complete remission; MM, multiple myeloma; MR, minimal response; NC, no change; ORR, overall response rate; PD, progressive disease; PR, partial response. 


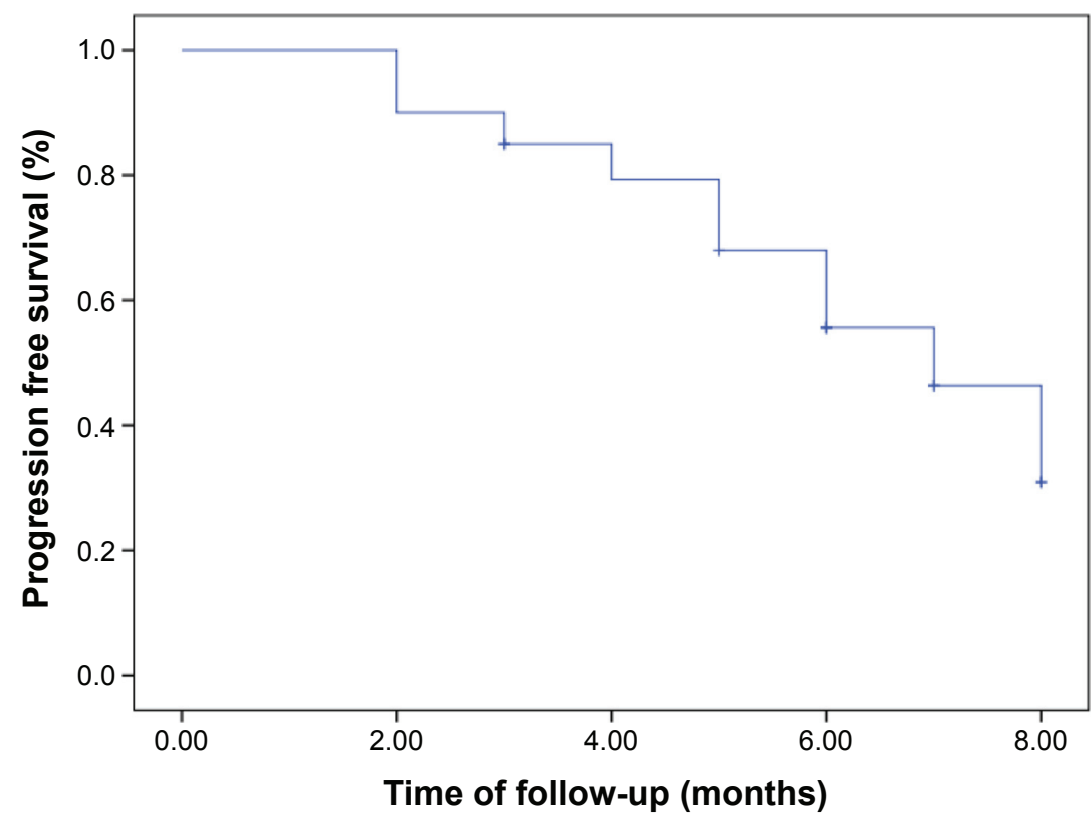

Figure 2 The time of PFS for the relapse and refractory MM patients treated with arsenic trioxide, ascorbic acid, ifosfamide, and prednisone. Abbreviations: MM, multiple myeloma; PFS, progression-free survival.

respiratory tract infection, and one had urinary tract inflammation). Seven patients had elevated transaminase during therapy, which was controlled using tiopronin injection to protect the liver. Arrhythmia was observed in four patients after therapy and needed drugs for control (Table 3 ).

\section{Discussion}

$\mathrm{MM}$ is characterized by clonal proliferation of malignant plasma cells in the bone marrow associated, in most patients, with the production of monoclonal Igs. Despite several recent therapeutic advances, including the bortezomib and lenalidomide treatments for MM, MM remains incurable; almost all patients eventually relapse and develop drug resistance. And there are few effective salvage regimens available for patients with disease resistant to the newer agents. Therefore, there is a clear need for improved salvage regimens in MM. $\mathrm{As}_{2} \mathrm{O}_{3}$ is the essential component of the Chinese medicine arsenic. ${ }^{13}$ The use of $\mathrm{As}_{2} \mathrm{O}_{3}$ as a medicinal agent dates back

Table 3 Treatment-related adverse events

\begin{tabular}{ll}
\hline Event & Number of patients (\%) \\
\hline Neutropenia (grade I-2) & $25(83.3)$ \\
Fatigue (grade I-2) & $22(73.3)$ \\
Anemia & $2 \mathrm{I}(70)$ \\
Thrombocytopenia & $16(53.3)$ \\
Infection & $8(26.7)$ \\
Liver function profiles increased & $7(23.3)$ \\
Nausea/vomiting & $5(16.7)$ \\
Arrhythmia & $4(13.3)$ \\
\hline
\end{tabular}

2,000 years. $\mathrm{As}_{2} \mathrm{O}_{3}$ has demonstrated clinical activity in patients with newly diagnosed APL, producing CR in $83 \%-86 \%$ of patients and 3 -year OS rates of $79 \%-86 \%$. $\mathrm{As}_{2} \mathrm{O}_{3}$ has also recently emerged as an effective treatment for patients with relapsed or refractory APL. ${ }^{14,15}$

$\mathrm{As}_{2} \mathrm{O}_{3}$ has demonstrated remarkable efficacy in APL. ${ }^{16-19}$ Recently some reports have led to a renewed interest in $\mathrm{As}_{2} \mathrm{O}_{3}$ in the management of malignancies, ${ }^{20,21}$ especially those of hematologic origin, such as MM.

In a Phase II trial at the University of Arkansas, the activity of $\mathrm{As}_{2} \mathrm{O}_{3}$ was evaluated in 14 patients with relapsed $\mathrm{MM}$ refractory to conventional salvage therapy. $\mathrm{As}_{2} \mathrm{O}_{3}$ was administered at a dose of $0.15 \mathrm{mg} / \mathrm{kg}$ daily for 60 days. Responses were noted in three patients: one achieved $75 \%$ reduction in the monoclonal protein, and the other two achieved $50 \%$ and $25 \%$, respectively. Stable disease was observed in eight patients. ${ }^{22}$ So the therapy response to singleagent $\mathrm{As}_{2} \mathrm{O}_{3}$ for $\mathrm{MM}$ was not satisfactory.

Then what is the chemotherapy response for the combination of $\mathrm{As}_{2} \mathrm{O}_{3}$ ? The combination of $\mathrm{As}_{2} \mathrm{O}_{3}$ and bortezomib $\left(\mathrm{As}_{2} \mathrm{O}_{3}+\right.$ bortezomib) has been recently shown to enhance antimyeloma activity. Both bortezomib and $\mathrm{As}_{2} \mathrm{O}_{3}$ were shown to activate the $\mathrm{p} 38 \mathrm{MAPK}$ pathway. $\mathrm{As}_{2} \mathrm{O}_{3}$ combination with bortezomib could enhance the activating of the p38 MAPK pathways. ${ }^{23}$ One Phase I study assessed the feasibility of concomitant $\mathrm{As}_{2} \mathrm{O}_{3}$, ascorbic acid, and bortezomib for patients with relapsed/refractory $\mathrm{MM} . \mathrm{As}_{2} \mathrm{O}_{3}(0.25 \mathrm{mg} / \mathrm{kg})$ and ascorbic acid ( $1 \mathrm{~g}$ ) were given with an escalating dose 
of bortezomib ( $1 \mathrm{mg} / \mathrm{m}^{2}$ or $1.3 \mathrm{mg} / \mathrm{m}^{2}$ IV bolus on days 1 and 8 of a 21 -day cycle). The results showed that four (40\%) patients achieved clinical benefit, with one patient achieving a durable PR. No formal dose-limiting toxicities were encountered. ${ }^{24}$ Berenson et al assessed the safety and efficacy of MAC (melphalan, $\mathrm{As}_{2} \mathrm{O}_{3}$, and ascorbic acid) combination therapy for MM patients who failed more than two different prior regimens. Patients received melphalan $(0.1 \mathrm{mg} / \mathrm{kg}$ PO), $\mathrm{As}_{2} \mathrm{O}_{3}(0.25 \mathrm{mg} / \mathrm{kg} \mathrm{IV})$, and ascorbic acid (1 g IV) on days $1-4$ of week $1, \mathrm{As}_{2} \mathrm{O}_{3}$ and ascorbic acid twice weekly during weeks 2-5, and no treatment during week 6 of cycle 1 ; during cycles $2-6$, the schedule remained the same except $\mathrm{As}_{2} \mathrm{O}_{3}$ and ascorbic acid were given twice weekly in week 1. Objective responses occurred in 31 of 65 (48\%) patients, including two CR, $15 \mathrm{PR}$, and $14 \mathrm{MR}{ }^{25}$ The above study showed that $\mathrm{As}_{2} \mathrm{O}_{3}$ combined with other drugs could improve the response over the single $\mathrm{As}_{2} \mathrm{O}_{3}$.

In this study, we retrospectively analyzed clinical data of 30 relapsed and refractory $\mathrm{MM}$ patients treated by $\mathrm{As}_{2} \mathrm{O}_{3}$ combined with ascorbic acid, ifosfamide, and prednisone. These patients had received bortezomib and lenalidomide before and relapsed more than three times. There were 28/ 30 patients who had received bortezomib and 15/30 patients who received lenalidomide treatment before treatment by $\mathrm{As}_{2} \mathrm{O}_{3}$. These patients had received more than 10 chemotherapy cycles, and treatment selection was difficult for these patients. The results showed that the ORR was $66.7 \%$ (20/30 cases, with PR in five cases), 50\% (10/20 cases, with PR in five cases), and 40\% (2/5 cases, with PR in one case), respectively, after 2,4 , and 6 cycles of the therapy. This result was better than the reports from the aforementioned clinical trial of $\mathrm{As}_{2} \mathrm{O}_{3}$ as a single agent. It was difficult to receive a curative effect for these relapsed and refractory MM patients, so the ORR in this study included MR. The majority of patients attained MR when treated with $\mathrm{As}_{2} \mathrm{O}_{3}$ combined with ascorbic acid, ifosfamide, and prednisone in this study and an increased PR rate with the longer the course of treatment. This result further confirmed that $\mathrm{As}_{2} \mathrm{O}_{3}$ is an effective agent for relapsed patients and that response could be increased by combination with other chemotherapy drugs.

Arsenic is well-known as a toxic agent. ${ }^{26}$ Chronic exposure to low levels of environmental arsenic has been reported to increase the incidence of skin, liver, bladder, and lung cancers. Other commonly observed potential signs of arsenic poisoning include cardiomyopathy, renal failure, leukocytosis, gastrointestinal disorders (eg, nausea, vomiting, and diarrhea), fatigue, fever, headache, and cough. Despite its reputation as a poison, as a therapeutic entity, $\mathrm{As}_{2} \mathrm{O}_{3}$ has been generally well-tolerated. In this study, we observed that neutropenia (83.3\%), anemia (70\%), and thrombocytopenia $(53.3 \%)$ occurred in more than half of the patients, who required growth factor and blood infusion support. Fatigue was more common in this study, which was untreated. Eight patients developed infections (three had pneumonia, four had acute upper respiratory tract infection, and one had urinary tract inflammation) and required antibiotic. QT prolongation, a known side effect of $\mathrm{As}_{2} \mathrm{O}_{3}$ therapy, was uncommon in this study, occurring in only four patients, but required drug intervention.

$\mathrm{As}_{2} \mathrm{O}_{3}$ combined with ascorbic acid, ifosfamide and prednisone could be selected as a salvage therapy to treat relapsed and refractory MM patients before using new agents, such as bortezomib and lenalidomide. Patients achieving MR could attain a better response by increasing the course of $\mathrm{As}_{2} \mathrm{O}_{3}$. And the regimen of $\mathrm{As}_{2} \mathrm{O}_{3}$ combined with ascorbic acid, ifosfamide, and prednisone was better tolerated by MM patients. It may be a promising choice for MM patients in early relapsed phase, to achieve a much better response.

\section{Author contributions}

Sun Wan-Jun collected and assembled the data, analyzed data, drafted the article, and gave final approval. Li Xin contributed to the concept, design, interpretation of the data, critical revision, and gave final approval.

\section{Disclosure}

The authors report no conflicts of interest in this work.

\section{References}

1. Mateos MV, San Miguel JF. Bortezomib in multiple myeloma. Best Pract Res Clin Haematol. 2007;20(4):701-715.

2. Wu X, Shi J, Wu Y, et al. Arsenic trioxide-mediated growth inhibition of myeloma cells is associated with an extrinsic or intrinsic signaling pathway through activation of TRAIL or TRAIL receptor 2. Cancer Biol Ther. 2010;10(11):1201-1214.

3. Lunghi P, Giuliani N, Mazzera L, et al. Targeting MEK/MAPK signal transduction module potentiates ATO-induced apoptosis in multiple myeloma cells through multiple signaling pathways. Blood. 2008;112(6): $2450-2462$.

4. Wang ZY, Chen Z. Acute promyelocytic leukemia: from highly fatal to highly curable. Blood. 2008;111(5):2505-2515.

5. Kluck RM, Bossy-Wetzel E, Green DR, Newmeyer DD. The release of cytochrome $\mathrm{c}$ from mitochondria: a primary site for Bcl-2 regulation of apoptosis. Science. 1997;275(5303):1132-1136.

6. Nishikawa M. Reactive oxygen species in tumor metastasis. Cancer Lett. 2008;266(1):53-59.

7. Kapahi P, Takahashi T, Natoli G, et al. Inhibition of NF-kappa B activation by arsenite through reaction with a critical cysteine in the activation loop of Ikappa B kinase. J Biol Chem. 2000;275(46):36062-36066.

8. Hussein MA, Mason J, Saleh NM, et al. Arsenic trioxide (Trisenox) in patients with relapsed or refractory multiple myeloma (MM): final report of a phase II clinical study. Proc Annu Meet Am Soc Hematol. 2002:5138. Abstract. 
9. Wang Y, Fang MY. Effect of ginseng saponin, arsenic trioxide, beta-elemene combined with CTX on telomere-telomerase system in K562 cell line. Zhongguo Shi Yan Xue Ye Xue Za Zhi. 2006;14(6):1089-1095.

10. Greipp PR, San Miguel J, Durie BG, et al. International staging system for multiple myeloma. J Clin Oncol. 2005;23:3412-3420.

11. Bladé J, Samson D, Reece D, et al. Criteria for evaluating disease response and progression in patients with multiple myeloma treated by high-dose therapy and haemopoietic stem cell transplantation. Myeloma Subcommittee of the EBMT. European Group for Blood and Marrow Transplant. Br J Haematol. 1998;102(5):1115-1123.

12. Durie BG, Harousseau JL, Miguel JS, et al. Internation uniform response criteria for multiple myeloma. Leukemia. 2006;2(9):1467-1473.

13. Zhou J. Arsenic trioxide: an ancient drug revived. Chin Med J (Engl). 2012;125(19):3556-3560.

14. Mathews V, George B, Lakshmi KM, et al. Single-agent arsenic trioxide in the treatment of newly diagnosed acute promyelocytic leukemia: durable remissions with minimal toxicity. Blood. 2006; 107(7):2627-2632.

15. Lou Y, Suo S, Tong Y, et al. Outcomes and prognostic factors of first relapsed acute promyelocytic leukemia patients undergoing salvage therapy with intravenous arsenic trioxide and chemotherapy. Ann Hematol. 2014;93(6):941-948.

16. Li X, Sun W, Li Z, et al. A survival study and prognostic factors analysis on acute promyelocytic leukemia at a single center. Leuk Res. 2007; 31(16):765-771.

17. Hu J, Liu YF, Wu CF, et al. Long-term efficacy and safety of all-trans retinoic acid/arsenic trioxide-based therapy in newly diagnosed acute promyelocytic leukemia. Proc Natl Acad Sci U S A. 2009;106(9): 3342-3347.

18. Ravandi F, Estey E, Jones D, et al. Effective treatment of acute promyelocytic leukemia with all-trans-retinoic acid, arsenic trioxide, and gemtuzumab ozogamicin. J Clin Oncol. 2009;27(4):504-510.
19. Gore SD, Gojo I, Sekeres MA, et al. Single cycle of arsenic trioxide-based consolidation chemotherapy spares anthracycline exposure in the primary management of acute promyelocytic leukemia. J Clin Oncol. 2010; 28(6): 1047-1053.

20. Kritharis A, Bradley TP, Budman DR. The evolving use of arsenic in pharmacotherapy of malignant disease. Ann Hematol. 2013; 92(6):719-730.

21. Takahashi S. Combination therapy with arsenic trioxide for hematological malignancies. Anticancer Agents Med Chem. 2010;10(6):504-510.

22. Munshi NC, Tricot G, Desikan R, et al. Clinical activity of arsenic trioxide for the treatment of multiple myeloma. Leukemia. 2002;16(9): $1835-1837$.

23. Wen J, Feng Y, Huang W, et al. Enhanced antimyeloma cytotoxicity by the combination of arsenic trioxide and bortezomib is further potentiated by p38 MAPK inhibition. Leuk Res. 2010;34(1):85-92.

24. Held LA, Rizzieri D, Long GD, et al. A Phase I study of arsenic trioxide (Trisenox), ascorbic acid, and bortezomib (Velcade) combination therapy in patients with relapsed/refractory multiple myeloma. Cancer Invest. 2013;31(3):172-176.

25. Berenson JR, Boccia R, Siegel D, et al. Efficacy and safety of melphalan, arsenic trioxide and ascorbic acid combination therapy in patients with relapsed or refractory multiple myeloma: a prospective, multicentre, phase II, single-arm study. Br J Haematol. 2006;135(2):174-183.

26. Agency for Toxic Substances and Disease Registry. Public Health Statement: Arsenic [publication CAS\# 7440-38-2]. Atlanta, GA: US Dept of Health and Human Services; 2007.
OncoTargets and Therapy

\section{Publish your work in this journal}

OncoTargets and Therapy is an international, peer-reviewed, open access journal focusing on the pathological basis of all cancers, potential targets for therapy and treatment protocols employed to improve the management of cancer patients. The journal also focuses on the impact of management programs and new therapeutic agents and protocols on

\section{Dovepress}

patient perspectives such as quality of life, adherence and satisfaction. The manuscript management system is completely online and includes a very quick and fair peer-review system, which is all easy to use. Visit http://www.dovepress.com/testimonials.php to read real quotes from published authors. 